\title{
An in-depth multidimensional review of hypertension in adolescents in relation to obesity: Risk approach management is the solution
}

\author{
Azza Abul-Fadl ${ }^{1}$, Ayoub Al-Jawaldeh ${ }^{2}$ \\ From ${ }^{1}$ Professor, Department of Pediatrics, Benha Faculty of Medicine, Benha University, Egypt, ${ }^{2}$ Regional Advisor Nutrition, Nutrition Unit, Eastern \\ Mediterranean Regional office - World Health Organization in Cairo, Egypt.
}

\begin{abstract}
Background: The emergence of isolated high blood pressure (HBP) among adolescents and its relation to obesity needs to be investigated. Aim: This study aims to assess prevalence, underlying risk factors, and consequences of HBP among adolescents in Egypt. Methods: We consolidated findings from three studies. The first one examined 150 adolescents (age: 16-18 years) for HBP and obesity using body mass index (BMI); the second one studied 150 adolescents for the lifestyle risk factors in relation to depression, anxiety, general health score, and suicidal score (SS) using relevant tools; the third one was a nested case-control study of 60 obese versus 60 non-obese adolescents examined for HBP, BMI, lifestyles and dietary habits, biochemical markers as lipid profile, fasting blood sugar (FBS), insulin, and homeostatic model assessment for insulin resistance (HOMA-IR). Results: In Stage I, the prevalence of HBP was $8 \%$ of whom, $58.3 \%$ were obese. Stage II: Dietary risk behavior as junk foods (high in salt) and soft drinks was $75.3 \%$ and $80 \%$, respectively, and was linked with a high SS. Smoking was associated with a high anxiety score $(\mathrm{p}<0.05)$ and not playing sports with a higher depression score $(\mathrm{p}<0.05)$. The nested case-control study for obese versus non-obese showed that HBP $($ both systolic and diastolic) was significantly higher in the obese. Consumption of junk foods, sugary drinks, and inactivity was significantly higher in the obese $(p<0.05)$. Lipid profile, FBS, fasting insulin, and HOMA-IR were significantly higher in the obese group versus non-obese control group $(\mathrm{p}<0.05)$. Conclusion: Lifestyle and unhealthy diet are the underlying cause of HBP, obesity, and mental health problems including SS, atherosclerosis, and high FBS. Increasing awareness about risk factors and using them in clinical practice for early detection of HBP is recommended.
\end{abstract}

Key words: Isolated hypertension, Adolescents, Obesity, Depression, Anxiety, Blood pressure, Homeostatic model assessment for insulin resistance

$\mathrm{H}$ igh blood pressure (HBP) and obesity are major public health problems throughout the world including in Egypt [1]. Although HBP is a disease of adults, it originally begins from early childhood and is linked to poor life styles and dietary practices. In recent years, secondary hypertension in children resulting from renal disease has become far less common than that related to primary hypertension. In the majority of cases of pediatric hypertension, the only formidable yet preventable etiological factor is obesity [2]. The global obesity epidemic has shifted blood pressure (BP) distribution toward childhood and adolescents [3]. It manifests as prehypertension in childhood progressing to HBP in adults. This is the "BP tracking" phenomenon which is used to detect individuals at risk of HBP [4].

\section{Access this article online}

Received - 21 August 2021

Initial Review - 31 August 2021

Accepted - 06 September 2021

DOI: $10.32677 / \mathrm{IJCH} .2021 . v 08.110 .3055$
High body mass index (BMI) has been reported to be characteristically associated with HBP [5] both systolic and diastolic BP [6]. Another study with Hispanic children showed increase of BMI correlated significantly with increase in systolic BP (SBP) but not with diastolic BP (DBP) [7]. This was also shown by a study in Egypt [8] where obese children and adolescents were 2.4 times more likely to have high DBP but 4.5 times more likely to have high SBP than their non-obese counterparts.

The problem of obesity is multisectoral and is linked with the sudden growth in technology of transport and communication that encourages sedentary life and the food industry that encourages fast food and junk food dietary patterns [6].

The aim of this study is to assess the prevalence of isolated HBP and its relation to obesity and its consequences and risk factors among adolescents in Egypt.

Correspondence to: Dr. Azza Abul-Fadl, Professor of Pediatrics, Faculty of Medicine, Benha University, 26B ElGezira AlWosta St. Zamalek, Cairo, 11211, Egypt. E-mail: azza_abulfadl@yahoo.com

(C) 2021 Creative Commons Attribution-NonCommercial 4.0 International License (CC BY-NC-ND 4.0). 


\section{MATERIALS AND METHODS}

The current study included two cross-sectional observational studies and one case control study conducted for Egyptian adolescents aged 16-18 years admitted to the faculty of medicine in Benha University, Qalyubia Governorate over the period of 2018-2019 through three thesis studies. The inclusion criteria for the third study were age: 17-19 years, males and females, attending the medical school of Benha. Exclusion criteria were severe disease, handicap, or subjects with mental disorder or on drugs or medication for a chronic disease. Ethical clearance for all three studies was obtained from the Institutional Ethical Committee of the Faculty of Medicine, Benha University.

The first stage was a study [9] for screening 150 adolescents (73 males and 77 females) for obesity and HBP using the following cutoffs of for both SBP and DBP; for pre-hypertension, that is, normal HBP (SBP=130-139 and $\mathrm{DBP}=85-89 \mathrm{mmHg})$, mild HBP ( $\mathrm{SBP}=140-159$ and $\mathrm{DBP}=90-99 \mathrm{mmHg}$ ), moderate HBP $(\mathrm{SBP}=160-179$ and $\mathrm{DBP}=100-109 \mathrm{mmHg}$ ), and severe HBP $(\mathrm{SBP}=180$ and $\mathrm{DBP}=110 \mathrm{mmHg}$ ). Anthropometric measurements for standing height and weight were carried using standard procedures for calculating BMI. Interpretation was done using the BMI for age. BMI categories for adults include underweight $=<18.5$, normal weight $=18.5-24.9$, overweight $=25-29.9$, and obesity $=\geq 30$. BMI growth charts used were those developed by the Egyptian Cairo University [10].

The second stage was a continuum of the previous study and involved screening of 150 students (88 males and 62 females) for risk factors and mental health [11]. The study methodology followed the same steps as the previous one but analyzed the risk factors in more detail related to physical activity, dietary consumption of foods rich in calories especially sugar and salt, fast foods, and sleep. It also analyzed the psychological status by conducting psychometric studies for depression using the Beck Depression Inventory (BDI) Arabic version [12] for individuals aged $\geq 13$. The standard cutoff scores are as follows: 0-9: No depression; 10-14: Borderline depression; 15-20: Mild depression; 21-30: Moderate depression; 31-40: Severe depression; 41-63: Extreme depression; and higher total scores indicate more severe depressive symptoms [13]. Anxiety was assessed by the anxiety scale by Costello and Comrey [14]. The third tool used was General Health Questionnaire-28 (GHQ- 28) [15]. The suicide score was estimated as a part of GHQ according to the score: 0: No suicidal tendency; 1-6: Mild; 7-12: Moderate; and 13-18: Severe suicidal tendency.
The third stage was a study [15] that focused on the risk factor of high BMI and physical health. It was a case-control study. BP and risk factors were assessed in relation to obesity. Laboratory studies included the lipid profile for total cholesterol, high-density lipoproteins (HDLs), and low-density lipoproteins (LDLs), triglycerides, fasting blood sugar (FBG), fasting insulin, and homeostatic model assessment for insulin resistance (HOMA-IR) using standard kits.

Statistical analysis was performed using the Statistical Package for the Social Sciences (IBM Corp. Released 2011 [IBM SPSS Statistics for Windows, Version 20.0]). Descriptive statistics included mean with standard deviation $( \pm \mathrm{SD})$ and range for parametric numerical data. Student's t-test was used to assess the statistical significance of the difference between two study group means. Chi-square test was used to examine the relationship between two qualitative variables. Fisher's exact test was used to examine the relationship between two qualitative variables when the expected count is $<5$ in more than $20 \%$ of cells. $p<0.05$ is considered statistically significant.

\section{RESULTS}

The first study presents the mean weight, height, BMI, SBP, DBP, and radial pulse and their mean centile and ranges in Egyptian adolescents admitted to faculty of medicine in Benha University (Table 1). This was the first stage that leads us to perform the second study.

The second study showed more lifestyle and mental health details about the population under study. There was no significant relationship between obesity and depression score, anxiety, or suicidal tendency $(\mathrm{p}>0.05)$. However, analysis of the risk factors did show significant findings with depression, anxiety general health score (GHS), and suicide tendency, as shown in Table 2.

The third study was a case control for obesity and its associated effects on the health of these children. The same risk factors in study 2 were present in the obese of study 3 versus non-obese (Table 3) and there were evident alterations in lipid profile, FBS, fasting insulin, and HOMA-IR in overweight and obese versus non-obese adolescents (Table 4).

We extrapolated the local findings of HBP and high BMI to the national level using the data of the Ethiopian Demographic and Health Survey (EDHS) of 2008 [1]. We compiled the data of obesity and overweight in this age group with HBP for the same age group. The findings showed a strong correlation between obesity and HBP (r0.785) at $\mathrm{p}<0.01$ and overweight ( $\mathrm{r} 0.72)$ at $\mathrm{p}<0.01$, as shown in Fig. 1 .

Table 1: Mean and centile mean of the weight, height, body mass index, and systolic and diastolic blood pressure in Egyptian freshman students of the Faculty of Medicine in Benha University (Study 1)

\begin{tabular}{lcccc}
\hline & Range & Mean \pm SD & Centile range & Centile Mean \pm SD \\
\hline Weight $(\mathrm{kg})$ & $50-95$ & $65.1 \pm 6.8$ & $12^{\text {th }}-98^{\text {th }}$ & $2^{\text {nd }-99^{\text {th }}}$ \\
Height $(\mathrm{cm})$ & $154-179$ & $166 \pm 4.8$ & $19^{\text {th }}-97^{\text {th }}$ & $38.7 \pm 21.9$ \\
BMI & $19-33$ & $23.6 \pm 2.3$ & \\
SBP & $90-150$ & $116 \pm 11.5$ & & \\
DBP & $60-90$ & $72.2 \pm 7.6$ & & \\
\hline
\end{tabular}

SD: Standard deviation, BMI: Body mass index, SBP: Systolic blood pressure, DBP: Diastolic blood pressure 


\section{DISCUSSION}

The findings of the prevalence of HBP and pre-HBP, their prevalence as per gender as well as body weight in the first study [9], were in accord with the national survey [1] that showed that percent prevalence of HBP and pre-HBP among adolescents aged 15-19 years was 9.6 and 4.2 in males and 7.8 and 2.9 in females, respectively. Overall percent prevalence of HBP in adolescents aged 15-19 years was 3.8 in females and 4.9 in males indicating a progressive increase in HBP among adolescents in Egypt.

A study in Port-Said [16] among Egyptians aged 12-15 years showed that SBP was significantly higher in the obese and overweight groups versus non-obese $(\mathrm{p}<0.001)$. In Alexandria, HBP prevalence among obese adolescents was $17.3 \%$ by BMI and $39 \%$ by waist circumference (WC) with an odds ratio of 3.5 and 7.3, respectively [17]. Another study among obese adolescents showed that the metabolic syndrome was detected 5 times more among the females [18]. This indicates that obesity and its related risk factors are driving HBP rates among adolescents.

Astudy in Alexandria University [4] showed that the prevalence of pre-HBP in schoolchildren was 9.5\% (boys: $8.9 \%$; girls: $9.9 \%$ ) and HBP was $5.2 \%$ (boys: $5.6 \%$; girls: $4.8 \%$ ). This shows that the prevalence of HBP is increasing even among the schoolaged students. They also showed that obesity was significantly higher among children with HBP (44.7\%) and pre-HBP (11.6\%) than among the normotensive children (8.7\%). Another study conducted for school-aged children reported that HBP was detected in $11.6 \%$ children (males: $6.2 \%$; females: $5.4 \%$ ) [19]. These findings support the hypothesis of this study that isolated HBP is linked to the rising rates of obesity [4].

Diastolic HBP (DHBP) is commonly reported as more serious and increases with age. A comparison [4] between HBP in the early school-aged (6 and 9 years) and pre-pubertal children (aged 9 and 12 years) showed that DHBP was more common (62\%) than systolic HBP (SHBP) (20\%). The combined systolic and diastolic HBP was $18 \%$. This increased with age from $25.8 \%$ at age 6-9 years to $74.2 \%$ at age 9-14 years of age for both SHBP and DHBP. By gender, girls tended to have higher SHBP compared to males while males showed higher SHBP and DHBP [4].

A review of the prevalence of HBP in developed and developing countries reported that overall prevalence of HBP was $32.3 \%$ with the Latin America and Caribbean region reporting the highest estimates (39.1\%). Pooled prevalence estimate was also highest across upper middle-income countries (37.8\%) and lowest across low-income countries (23.1\%). There was no significant sex difference in HBP prevalence. Overweight, obesity, lower education, and urban settlers were at higher risk of HBP [20].

In the second study stage [11], we analyzed the factors that were associated with obesity and HBP among a similar group of adolescents from the same place and in the same period. The results showed that the prevalence of unhealthy dietary risk behaviors as consuming junk foods and intake of soft drinks was high and linked with a high suicidal score (SS) for the former and GHS and SS for the latter. Smoking was associated with a high anxiety score $(\mathrm{p}<0.05)$ and not playing sports with a higher depression score $(\mathrm{p}<0.05)$.

On extrapolating our findings to the EDHS [1], we found that HBP correlated significantly with obesity and overweight. By region, HBP remained consistent, but BMI was characteristically higher in urban region compared to their rural counterparts. By level of education, there was a consistent relationship between HBP and obesity but not overweight with HBP and obesity rising in those with some primary and again

Table 2: Risk factors for hypertension and obesity, in relation to the depression score, anxiety score, GHS, and suicidal score among the Egyptian students from the Faculty of Medicine, Benha University (Study 2)

\begin{tabular}{|c|c|c|c|c|c|c|}
\hline Risk factor & Number & Percentage & $\begin{array}{c}\text { Depression score } \\
(\text { Mean } \pm \text { SD) }\end{array}$ & $\begin{array}{l}\text { Anxiety score } \\
(\text { Mean } \pm \text { SD) }\end{array}$ & $\begin{array}{c}\text { General health score } \\
(\text { Mean } \pm \text { SD })\end{array}$ & $\begin{array}{c}\text { Suicidal score } \\
(\text { Mean } \pm \text { SD) }\end{array}$ \\
\hline \multicolumn{7}{|l|}{ Smoking } \\
\hline Yes & 38 & 25.3 & $15.03 \pm 4.12$ & $40.74 \pm 12.93$ & $29.29 \pm 9.98$ & $6.03 \pm 3.21$ \\
\hline No & 112 & 74.7 & $\begin{array}{l}15.24 \pm 6.00 \\
\mathrm{p}=0.8 \text { (NS) }\end{array}$ & $\begin{array}{c}33.61 \pm 10.87 \\
\mathrm{p}=0.3(\mathrm{~S})\end{array}$ & $\begin{array}{c}30.94 \pm 10.72 \\
\mathrm{p}=0.3(\mathrm{NS})\end{array}$ & $\begin{array}{c}5.78 \pm 3.18 \\
\mathrm{p}=0.6(\mathrm{NS})\end{array}$ \\
\hline \multicolumn{7}{|c|}{ Play competitive sports } \\
\hline Yes & 42 & 28 & $12.34 \pm 5.78$ & $36.75 \pm 13.94$ & $28.37+11.44$ & $5.38+2.86$ \\
\hline No & 108 & 62.7 & $\begin{array}{l}17.69 \pm 5.41 \\
\mathrm{p}=0.03(\mathrm{~S})\end{array}$ & $\begin{array}{c}38.66 \pm 11.55 \\
p=0.3(\mathrm{NS})\end{array}$ & $\begin{array}{l}32.20 \pm 9.95 \\
\mathrm{p}=0.03(\mathrm{~S})\end{array}$ & $\begin{array}{c}6.12 \pm 3.33 \\
\mathrm{p}=0.17(\mathrm{NS})\end{array}$ \\
\hline \multicolumn{7}{|c|}{ Consume junk foods } \\
\hline Yes & 113 & 75.32 & $15.44 \pm 5.44$ & $37.19 \pm 12.97$ & $30.88 \pm 10.61$ & $6.20 \pm 3.21$ \\
\hline No & 37 & 4.7 & $\begin{array}{l}14.41 \pm 5.97 \\
\mathrm{p}>0.05\end{array}$ & $\begin{array}{c}40.27 \pm 10.70 \\
p>0.05\end{array}$ & $\begin{array}{c}29.41 \pm 10.34 \\
\mathrm{p}>0.05\end{array}$ & $\begin{array}{l}4.73 \pm 2.82 \\
p=0.01(S)\end{array}$ \\
\hline \multicolumn{7}{|c|}{ Drink sugary beverages } \\
\hline Yes & 120 & 80.0 & $15.41 \pm 5.60$ & $37.91 \pm 12.72$ & $31.40 \pm 10.56$ & $6.20 \pm 3.24$ \\
\hline No & 30 & 20.0 & $\begin{array}{l}14.30 \pm 5.48 \\
\mathrm{p}>0.05\end{array}$ & $\begin{array}{c}38.10 \pm 11.69 \\
\mathrm{p}>0.05\end{array}$ & $\begin{array}{l}27.00 \pm 9.80 \\
\mathrm{p}=0.04(\mathrm{~S})\end{array}$ & $\begin{array}{c}4.40 \pm 2.46 \\
\mathrm{p}=0.001(\mathrm{HS})\end{array}$ \\
\hline \multicolumn{7}{|c|}{ Eating while watching TV } \\
\hline Yes & 124 & 82.7 & $15.23 \pm 5.71$ & $37.37 \pm 12.89$ & $30.87 \pm 10.83$ & $6.03 \pm 3.32$ \\
\hline No & 120 & 17.3 & $\begin{array}{c}15.00 \pm 4.97 \\
\mathrm{p}>0.05\end{array}$ & $\begin{array}{c}40.69 \pm 10.11 \\
p>0.05\end{array}$ & $\begin{array}{c}28.85 \pm 8.94 \\
p>0.05\end{array}$ & $\begin{array}{c}4.92 \pm 2.19 \\
p>0.05\end{array}$ \\
\hline
\end{tabular}

SD: Standard deviation, p: Probability value, NS: Non-significant, S: Significant, HS: Highly significant 
Table 3: Comparison of demographic data, lifestyle, and dietary habits in the overweight and obese versus control group (study 3)

\begin{tabular}{|c|c|c|c|}
\hline Parameter & $\begin{array}{c}\begin{array}{c}\text { Control group } \\
(n=60)\end{array} \\
\end{array}$ & $\begin{array}{c}\text { Obese group } \\
(n=60)\end{array}$ & p value \\
\hline Age (years) & $17.4 \pm 1.0$ & $17.5 \pm 0.8$ & $>0.05(\mathrm{NS})$ \\
\hline No. of family members & $6 \pm 2$ & $6 \pm 2$ & $>0.05(\mathrm{NS})$ \\
\hline \multicolumn{4}{|c|}{ Mother education (percentage) } \\
\hline Illiterate & $8(13 \%)$ & $17(28 \%)$ & $>0.05(\mathrm{NS})$ \\
\hline Primary & $11(18 \%)$ & $19(32 \%)$ & $>0.05(\mathrm{NS})$ \\
\hline Secondary & $21(35 \%)$ & $14(23 \%)$ & $>0.05(\mathrm{NS})$ \\
\hline High & $20(33 \%)$ & $10(17 \%)$ & $>0.05(\mathrm{NS})$ \\
\hline \multicolumn{4}{|l|}{ Residence (percentage) } \\
\hline Urban & $41(68 \%)$ & $28(47 \%)$ & $<0.05(\mathrm{~S})$ \\
\hline Rural & $19(32 \%)$ & $32(53 \%)$ & $<0.05(\mathrm{~S})$ \\
\hline \multicolumn{4}{|l|}{ Sex (percentage) } \\
\hline Male & $28(47 \%)$ & $32(53 \%)$ & $>0.05(\mathrm{NS})$ \\
\hline Female & $32(53 \%)$ & $28(47 \%)$ & $>0.05(\mathrm{NS})$ \\
\hline \multicolumn{4}{|l|}{ Dietary habits (percentage) } \\
\hline \multicolumn{4}{|l|}{ Fast food } \\
\hline Daily & $0(0 \%)$ & $36(60 \%)$ & $<0.05(\mathrm{~S})$ \\
\hline Weekly & $28(47 \%)$ & $15(25 \%)$ & $<0.05(\mathrm{~S})$ \\
\hline Monthly & $32(53 \%)$ & $9(15 \%)$ & $<0.05(\mathrm{~S})$ \\
\hline \multicolumn{4}{|c|}{ Fruits and vegetables (percentage) } \\
\hline Yes & $33(55 \%)$ & $26(43 \%)$ & $>0.05(\mathrm{NS})$ \\
\hline No & $27(45 \%)$ & $34(57 \%)$ & $>0.05(\mathrm{NS})$ \\
\hline \multicolumn{4}{|c|}{ Sugary beverages (percentage) } \\
\hline Yes & $14(23 \%)$ & $43(72 \%)$ & $<0.05(\mathrm{~S})$ \\
\hline No & $46(77 \%)$ & $17(28 \%)$ & $<0.05(\mathrm{~S})$ \\
\hline \multicolumn{4}{|l|}{ Lifestyle habits (percentage) } \\
\hline \multicolumn{4}{|l|}{ Physical activity } \\
\hline No sport & $6(10 \%)$ & $29(48 \%)$ & $<0.05(\mathrm{~S})$ \\
\hline Some sport & $25(42 \%)$ & $19(32 \%)$ & $<0.05(\mathrm{~S})$ \\
\hline Competitive sport & $29(48 \%)$ & $12(20 \%)$ & $<0.05(\mathrm{~S})$ \\
\hline \multicolumn{4}{|l|}{ Smoking (percentage) } \\
\hline Yes & $6(10 \%)$ & $13(22 \%)$ & $>0.05$ (NS) \\
\hline No & $54(90 \%)$ & $47(78 \%)$ & $<0.05(\mathrm{~S})$ \\
\hline \multicolumn{4}{|l|}{ Pattern of sleep (percentage) } \\
\hline Early rise & $28(47 \%)$ & $23(38 \%)$ & $>0.05$ (NS) \\
\hline Late rise & $32(53 \%)$ & $37(62 \%)$ & $>0.05(\mathrm{NS})$ \\
\hline Watching TV (h/day) & $2 \pm 1$ & $5 \pm 1$ & $<0.05(\mathrm{~S})$ \\
\hline Hours of sleeping (h/day) & $8 \pm 1$ & $11 \pm 1$ & $<0.05(\mathrm{~S})$ \\
\hline
\end{tabular}

NS: Non-significant, S: Significant, p: Probability value

among those with higher education. Our findings are supported by other who reported that the risk factors associated with HBP included adding table salt, regular consumption of certain energy dense foods, and certain types of salty foods and foods with high sodium content (OR 2.6). Snacking and less physical activity among children had a higher risk for HBP (OR 2.5) [4]. In Qalyubia, school-aged children with prehypertension or HBP were 4 times less likely to practice sports [21]. HBP was more prevalent in private than in public schools [22]. Children with HBP and obesity were found to eat snacks, drink sugary beverages on regular basis, and do less exercise [17,22]. HBP was more prevalent in obese versus overweight (22\% vs. $6.4 \%$ ) and WC was reported to be a good indicator of HBP, especially Grade III [23].

HBP and obesity increased with age. A study conducted for primary schoolchildren in Menoufia in Egypt showed that prehypertension was $2.8 \%$ in males and $5.2 \%$ in females who were overweight and obese. They found that HBP was directly proportional to the increase in age in both sexes [24].

A systematic review and meta-analysis of HBP in children showed that prevalence rate of prehypertension was $4 \%$ and of HBP was $4 \%$ mostly Stage I hypertension and $0.95 \%$ for Stage II for children below 19 years of age. The study was based on HBP measured on three consecutive visits [25]. 
Table 4: Comparison of the mean overweight and obese versus non-obese regarding lipid profile and fasting blood sugar, fasting insulin, and HOMA-IR

\begin{tabular}{|c|c|c|c|c|c|}
\hline \multirow[t]{2}{*}{ Parameter } & \multicolumn{2}{|c|}{ Cases $(n=60)$} & \multirow[t]{2}{*}{ p value (overweight vs. obese) } & \multirow[t]{2}{*}{ Controls $(n=60)$} & \multirow{2}{*}{$\begin{array}{c}\text { p value (cases vs } \\
\text { controls) }\end{array}$} \\
\hline & Overweight $(n=26)$ & Obese $(n=34)$ & & & \\
\hline \multicolumn{6}{|l|}{ Lipid profile } \\
\hline Triglycerides (mmol/l) & $1.3 \pm 0.4$ & $1.2 \pm 0.4$ & $>0.05(\mathrm{NS})$ & $0.87 \pm 0.39$ & $<0.05(\mathrm{~S})$ \\
\hline $\begin{array}{l}\text { Total } \\
\text { cholesterol }(\mathrm{mmol} / \mathrm{l})\end{array}$ & $4.5 \pm 0.7$ & $4.2 \pm 0.9$ & $>0.05(\mathrm{NS})$ & $3.64 \pm 0.78$ & $<0.05$ (S) \\
\hline $\begin{array}{l}\text { LDL } \\
\text { cholesterol (mmol/l) }\end{array}$ & $2.5 \pm 0.7$ & $2.1 \pm 0.9$ & $>0.05$ (NS) & $2.00 \pm 0.54$ & $<0.05(\mathrm{~S})$ \\
\hline $\begin{array}{l}\text { HDL } \\
\text { cholesterol }(\mathrm{mmol} / \mathrm{l})\end{array}$ & $1.2 \pm 0.3$ & $1.3 \pm 0.3$ & $>0.05(\mathrm{NS})$ & $1.35 \pm 0.31$ & $>0.05(\mathrm{NS})$ \\
\hline \multicolumn{6}{|l|}{ Cardiac vitals } \\
\hline Heart rate (BPM) & $74 \pm 10$ & $73 \pm 10$ & $>0.05(\mathrm{NS})$ & $71 \pm 10$ & $>0.05(\mathrm{NS})$ \\
\hline $\mathrm{SBP}(\mathrm{mmHg})$ & $117 \pm 12$ & $116 \pm 12$ & $>0.05(\mathrm{NS})$ & $105 \pm 12$ & $<0.05(\mathrm{~S})$ \\
\hline $\mathrm{DBP}(\mathrm{mmHg})$ & $62 \pm 7$ & $63 \pm 8$ & $>0.05(\mathrm{NS})$ & $59 \pm 8$ & $<0.05(\mathrm{~S})$ \\
\hline \multicolumn{6}{|l|}{ Glycemic status } \\
\hline $\begin{array}{l}\text { Fasting } \\
\text { glucose }(\mathrm{mmol} / \mathrm{l})\end{array}$ & $4.6 \pm 0.6$ & $4.8 \pm 0.5$ & $>0.05(\mathrm{NS})$ & $4.4 \pm 0.5$ & $<0.05(\mathrm{~S})$ \\
\hline Fasting insulin (pmol/1) & $126.9 \pm 38$ & $130.4 \pm 38.2$ & $>0.05(\mathrm{NS})$ & $62.3 \pm 15.2$ & $<0.05(\mathrm{~S})$ \\
\hline HOMA-IR & $3.9 \pm 1.2$ & $4.0 \pm 1.1$ & $>0.05(\mathrm{NS})$ & $1.9 \pm 0.4$ & $<0.05(\mathrm{~S})$ \\
\hline
\end{tabular}

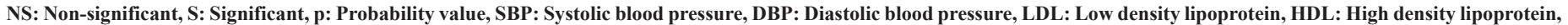
HOMA-IR: Homeostatic model assessment for insulin resistance

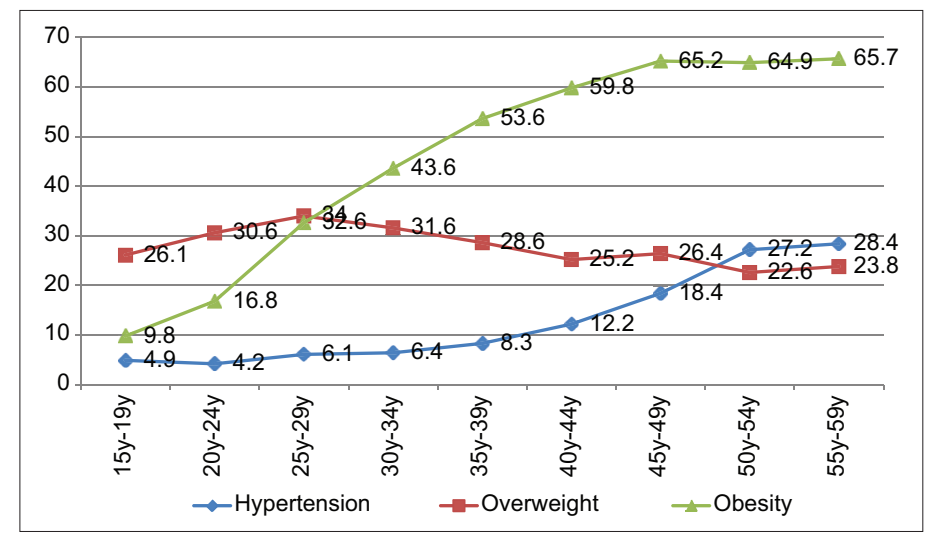

Figure 1: Egypt demographic health survey findings of hypertension, overweight, and obesity by age group

In the current study, we showed that risk factors of obesity were associated with mental health issues. Smoking increased anxiety score. Exercise lowered depression score and improved GHS. Eating junk foods and drinking soda were associated with a high SS. A large-scale study [26] reported that $13 \%$ had a baseline diagnosis of anxiety and/or depression that were linked to HBP [26]. Research indicates that there is significant cooccurrence of hypertension with anxiety, depression, and chronic pain which may lead to undertreatment of both HBP and the underlying mental health disorders [27]. The association between mental health and HBP is complex and is modulated by physiologic and environmental factors [27].

We found a high association between anxiety and cigarette smoking. Smoking is a powerful cardiovascular disease (CVD) risk factor and smoking cessation is the single most effective lifestyle measure for the prevention of CVD. Hypertensive smokers are more likely to develop severe forms of hypertension, including malignant and renovascular hypertension, an effect likely due to an accelerated atherosclerosis [28]. Smoking with obesity jointly increase all-cause mortality from CVD [29]. Smoking, high BMI, and diabetes mellitus also increase all-cause mortality from CVD even more [29].

In third stage of our study [30], obese and HBP adolescents showed at risk lipid profiles of atherosclerosis and high-risk patterns of impaired glucose homeostasis (pre-diabetes). The EDHS survey showed that diabetes mellitus was reported in $14 \%$ of those with prehypertension, $24.7 \%$ in mild, and $0.4 \%$ in males, respectively. Coronary heart disease (CHD) was reported among pre-HBP, those with mild HBP, moderate HBP, and severe HBP in $23.4,6.6,28.4 \%$ and $5.6 \%$ in males and $11.5 \%, 12 \%$ and $2.4 \%$ and $0.0 \%$ in females, respectively [1].

Obesity-related HBP appears to be associated with the same hormonal substances (cytokines) produced by adipose tissue that result in hyperinsulinemia and the frequent development of type 2 diabetes. It has been suggested that hyperinsulinemia increases sodium absorption. Kidney abnormalities affecting sodium and water reassertion are significantly correlated with obesity-related HBP [8]. High salt intake is also associated with HBP as shown in our studies for high intake of junk foods. In Egypt, the consumption of salt is 3.7\% [31]. Scaling up policies for reducing salt intake in diet is underway in Egypt and in the Eastern Mediterranean region [32].

The national survey [1] showed that public awareness of the consequences of HBP was poor as this makes $74 \%$ of females and $85 \%$ of males at risk of complications of HBP in Egypt. A cross-sectional study of pooled individual-level populationbased data from 44 low- and middle-income countries showed that the prevalence of HBP was $17.5 \%$ of whom $75 \%$ had never measured their BP, 39\% were diagnosed as HBP, but only $10 \%$ were controlled [33]. 
A review of educational strategies to prevent diabetes, HBP, and obesity showed that the most efficient interventions occurred at community level, whenever the intervention was permanent or maintained for long periods, and relied on the continuous education of community health workers with a focus on children and adolescents as the knowledge acquired by them could spread to their family and to the society [34]. Early detection and compliance to treatment have been higher in high-income countries versus low-income countries [35].

A study in India to evaluate the impact of a school-based health and nutritional education program on knowledge and behavior of urban schoolchildren aged 8-18 years showed that a significantly higher improvement was observed in younger children (aged 8-11 years) as compared with those aged $12-18$ years and in government schools compared with private schools ( $\mathrm{p}<0.05$ for all) [36].

Most studies indicate that HBP and obesity are closely related and contribute further to the risks for CVD. Timely diagnosis and initiation of treatment are important. First-line interventions should aim for BP control and weight reduction. Lifestyle modifications and antihypertensive treatment are recommended for all hypertensive children with failure of non-pharmacological treatment, diabetes, secondary HBP, Stage $2 \mathrm{HBP}$, or target organ damage [3]

However, the studies included in the current article, were conducted for a small number of adolescent students. We tried to overcome this by supporting our study by other studies conducted on similar populations. This is why we extrapolated this study to national data using the EDHS [1].

\section{CONCLUSION}

Prevalence of HBP among adolescents is high and is associated with obesity in both sexes. Risk factors include poor dietary habits as smoking, junk foods and sugary beverages, sedentary life, and lack of sports. These risk factors are linked with depression, anxiety, and suicidal tendencies. Obese subjects have HBP atherogenic lipid profile and diabetogenic tendencies. Hence, risk behavior and obesity can be used to detect CVD and HBP in adolescents [5].

It is recommended that countries monitor BMI and BP from early childhood by identifying the high-risk behavior among students, screen them for early detection of HBP, CVD, and DM, and reverse their lifestyles and dietary habits using positive psychology. Implementing policies and regulations to reduce salt in processed and readymade food, and exposure to tobacco while encouraging sports education and public sports areas are another approach for reducing HBP and obesity. Member states are encouraged, to exert pressure on industry to control their marketing tactics for promoting unhealthy foods and tobacco. The WHO should continue to play a key role in providing evidencebased tools for the planning, implementation, and surveillance of initiatives for tobacco control, healthy diets, and national salt reduction.

\section{DISCLAIMER}

The authors alone are responsible for the views expressed in this article and they do not necessarily represent the views, decisions or policies of the World Health Organization or the other institutions with which the authors are affiliated.

\section{REFERENCES}

1. Ministry of Health, El-Zanaty. Egypt Demographic and Health Survey 2008. Cairo, Egypt: Ministry of Health, El-Zanaty, Fatma and Ann Way, El-Zanaty and Associates, and Macro International; 2009.

2. Daniels SR. Understanding the global prevalence of hypertension in children and adolescents. JAMA Pediatr 2019;173:1133-4.

3. Wühl E. Hypertension in childhood obesity. Acta Paediatr 2019;108:37-43.

4. Kamel SG. Hypertension and its Relation to Obesity among Primary Care Children in Alexandria. Thesis, Master of Science Degree in Forensic Medicine. Supervised by Darwish OA, Sahn FAF, Tayel KY. Egypt: Faculty of Medicine, Alexandria University; 2010.

5. Csige I, Ujvárosy D, Szabó Z, Lőrincz I, Paragh G, Harangi M, et al. The impact of obesity on the cardiovascular system. J Diabetes Res 2018;2018:3407306.

6. Gundogdu Z. Relationship between BMI and blood pressure in girls and boys. Public Health Nutr 2008;11:1085-8.

7. Mirza NM, Kadow K, Palmer M, Solano H, Rosche C, Yanovski JA. Prevalence of overweight among inner city Hispanic-American children and adolescents. Obes Res 2012;12:1298-310.

8. El-Sewefy EZ. Prevalence of Hypertension among Obese Adolescents and Effect of Dietary Modification on Its Control. Thesis, Master of Science in Public Health. High Institute of Public Health. Egypt: Alexandria University; 2006.

9. El-Galy AH. Screening of Pre-University Students for Cardiovascular Disorders. Supervised by Abu-Fadl AMA, Kolkailah NA, Sobeh AA. Thesis, Master in Pediatrics, Faculty of Medicine, Benha University; 2017.

10. Ghalli I, Salah N, Hussien F, Erfan M, El-Ruby M, Mazen I, et al. Egyptian growth curves 2002 for infants, children and adolescents. In: Sartorio A, Buckler JM, Marazzi N, editors. Crescere Nel Mondo. Milan, Italy: Ferring Publisher; 2008.

11. Hossien RM. Screening of the First Year Medical Students of Benha University for Depression and Anxiety. Thesis, Master in Pediatrics. Supervised by Abul-Fadl AMA, El-Bakry ST, ElBehairy OG. Faculty of Medicine, Benha University; 2017.

12. Ghanem M, Gadallah M, Meky FA, Mourad S, El-Kholy G. National survey of prevalence of mental disorders in Egypt: Preliminary survey. East Mediterr Health J 2009; 15:65-75.

13. Beck AT, Ward CH, Mendelson M, Mock J, Erbaugh J. An inventory for measuring depression. Arch Gen Psychiatry 1961;4:561-71.

14. Costello CG, Comrey AL. Scales for measuring depression and anxiety. J Psychol 1967;66:303-13.

15. Goldberg D, Hillier VG. A scaled version of the general health questionnaire. Psychol Med 1979;9:139-45.

16. Kotb MB. Prevalence of Obesity among Adolescents Aged 12-15 Years in Port Said Governorate. Thesis, Master in Pediatrics. Supervised by Zeitoun A, Atef Saad A, Atwa HA. Faculty of Medicine, Suez Canal University, 2010-2011; 2011.

17. Loutfy AA. An Epidemiological Study on Blood Pressure among School Adolescents in Alexandria. Master thesis, High Institute of Public Health. Supervised by Sallam SA, AbouelFetouh MA, Mohamed MS. Egypt: Alexandria University; 2009.

18. Shaima AM. Prevalence of Obesity among Adolescents Aged 12-15 Years in Ismailia Governorate (Rural Areas). Thesis, Master in Pediatrics. Supervised by Atwa HA, Handoka NM. Faculty of Medicine, Suez Canal University; 2011.

19. Osman MA. Prevalence of Hypertension among Obese Primary School Children in Some Urban Areas in Qaluibiya Governorate. Supervised by Nady N, Soliman D. Thesis Master of Science in Pediatrics. Faculty of Medicine, Benha University; 2015. 
20. Sarki AM, Nduka CU, Stranges S, Kandala NB, Uthman OA. Prevalence of hypertension in low-and middle-income countries: A systematic review and meta-analysis. Medicine (Baltimore) 2015;94:e1959.

21. Mohamed MS. Prevalence of Hypertension among Obese Primary School Children in Some Rural Areas in Qaluibiya Governorate. Supervised by Nady N, El-Gaiaty H. Thesis Master of Science in Pediatrics. Faculty of Medicine, Benha University; 2015.

22. Osman MA. Prevalence of Hypertension among Obese Primary School Children in Some Urban Areas in Qaluibiya Governorate. Supervised by Nady N, Soliman DR. Thesis Master of Science in Pediatrics. Faculty of Medicine, Benha University; 2015.

23. Ismail HA. Assessment of Obesity and Its Relation to Blood Pressure in Primary School Children. Thesis Master in Pediatrics. Supervised by Tawfik MA, Abou ElAlla SS. Faculty of Medicine, Menoufia University; 2012.

24. Aziz AY. Growth Parameters and Blood Pressure Measurements in Primary School Children. Thesis, Master in Pediatrics. Supervised by Abou Elela SS, Abo Elfotoh WM. Faculty of Medicine, Menoufia University; 2019.

25. Song P, Zhang Y, Yu J, Zha M, Zhu Y, Rahimi K, et al. Global prevalence of hypertension in children: A systematic review and meta-analysis. JAMA Pediatr 2019;173:1154-63.

26. Ho AK, Thorpe CT, Pandhi N, Palta M, Smith MA, Johnson HM. Association of anxiety and depression with hypertension control: A US multidisciplinary group practice observational study. J Hypertens 2015;33:2215-22.

27. Hamam MS, Kunjummen E, Hussain MS, Nasereldin M, Bennett S, Miller J. Anxiety, depression, and pain: Considerations in the treatment of patients with uncontrolled hypertension. Curr Hypertens Rep 2020;22:106.

28. Virdis A, Giannarelli C, Neves MF, Taddei S, Ghiadoni L. Cigarette smoking and hypertension. Curr Pharm Des 2010;16:2518-25.

29. Håglin L, Törnkvist B, Bäckman L. Obesity, smoking habits, and serum phosphate levels predicts mortality after life-style intervention. PLoS One 2020;15:e0227692.

30. Shaheen SI. Tissue Doppler Studies for Assessment of Cardiovascular
Risk in Obese Adolescents. MD Thesis Pediatrics. Supervised by AbulFadl A, Dabour S, Bayoumi R, Alhusseini N. Faculty of Medicine, Benha University; 2017.

31. Tayel DI, Amine AK, Elzawi AK. Dietary intake of nutrients related to bone health among Alexandria University female students, Egypt. Food Public Health 2013;3:329-35.

32. Al-Jawaldeh A. Rafii B. Nasreddine L. Salt intake reduction strategies in the Eastern Mediterranean Region. East Mediterr Health J 2018;24:1172-80.

33. Geldsetzer P, Manne-Goehler J, Marcus ME, Ebert C, Zhumadilov Z, Wesseh CS, et al. The state of hypertension care in 44 low-income and middle-income countries: A cross-sectional study of nationally representative individual-level data from 1·1 Million adults. Lancet 2019;394:652-62.

34. Machado AP, Lima BM, Laureano MG, Silva PH, Tardin GP, Reis PS, et al. Educational strategies for the prevention of diabetes, hypertension, and obesity. Rev Assoc Med Bras (1992) 2016;62:800-8.

35. Mills KT, Bundy JD, Kelly TN, Reed JE, Kearney PM, Reynolds K, et al. Global disparities of hypertension prevalence and control: A systematic analysis of population-based studies from 90 countries. Circulation 2016;134:441-50.

36. Shah P, Misra A, Gupta N, Hazra DK, Gupta R, Seth P, et al. Improvement in nutrition-related knowledge and behaviour of urban Asian Indian school children: Findings from the Medical education for children/Adolescents for Realistic prevention of obesity and diabetes and for healthy aGeing (MARG) intervention study. Br J Nutr 2010;104:427-36.

Funding: None; Conflicts of Interest: None Stated.

How to cite this article: Abul-Fadl A, Al-Jawaldeh A. An in-depth multi-dimensional review of hypertension in adolescents in relation to obesity: Risk approach management is the solution. Indian J Child Health. 2021; 8(10):352-358. 